\title{
Planaria: Interspecific transfer of a conditionability factor through cannibalism
}

RAE S. RAGLAND AND JAMES B. RAGLAND

BAYLOR UNIVERSITY COLLEGE OF MEDICINE AND HOUSTON STATE PSYCHIATRIC INSTITUTE

\begin{abstract}
Using an instrumental avoidance training procedure, Dugesia dorotocephala can be conditioned while Dugesia tigrina cannot. D. tigrina become conditionable if they cannibalize conditioned $D$. dorotocephala. The conditionability factor apparently is a result of conditioning of D. dorotocephala since $D$. tigrina that cannibalize naive D. dorotocephala remain nonconditionable.
\end{abstract}

\section{Introduetion}

It has been reported that naive planaria can be conditioned in fewer trials if they have cannibalized other planaria that have been classically conditioned by a light-shock procedure (McConnell, 1962). Presumably the species $D$. dorotocephala was used as has been the case with most of the work from McConnell's laboratory . Hartry, Keith-Lee \& Morton (1964) repeated McConnell's work presumably with D. dorotocephala and in addition controlled the polarity of the shock. These investigators found that not only cannibals of previously conditioned planaria but cannibals of planaria receiving photic stimuli only, shock only or handling only also required fewer trials to criterion in a conditioning situation than did naive planaria. Hartry et al concluded that an explanation other than the "memory transfer" hypothesis could more adequately explain their findings.

Best \& Rubinstein (1962) and Lee (1963) have reported instrumental conditioning of the planarian Cura foremani. The former authors employed a Y-maze using light and dark as cues and addition of water as reinforcement for a correct choice. Lee conditioned a free operant response in which the response measured was the worm passing through a narrow beam of light, and reinforcement was termination of an intense light. More recently, right and left turn responses have been used to demonstrate discrimination between photic and vibratory stimuli in the planarian Phagocata gracilis (Griffard \& Peirce, 1964).

\section{Experimental}

Two species of planaria were used in an instrumental avoidance training procedure. D. tigrina and D. dorotocephala $l$ were maintained and tested in different salt solutions found to be optimum for each species. The optimum conditions for maintaining each species and factors affecting conditioning were investigated and will be reported in detail elsewhere. All worms were randomly selected from stock tanks and isolated in individual bowls maintained at room temperature in a constant light of $43 \mathrm{ft}-\mathrm{c}$. D. dorotocephala were isolated 10 days prior to the time that they were fed to D. tigrina. Conditioned D. dorotocephala to be canni- balized were trained by the procedure described below. The data for D. dorotocephala in Fig. 1 are derived from these worms.

The Ss consisted of eighteen D. tigrina divided into three groups of six. Prior to the experiments all Ss were starved for 10 days in order to encourage cannibalism. Twelve hours before the first block of trials was begun one group was fed liver, one was fed naive D. dorotocephala and one was fedconditioned D. dorotocephala. Each of the D. dorotocephala to be cannibalized was briefly soaked in $20 \%$ liver homogenate and cut into nine pieces. Soaking in liver homogenate was used because this treatment appeared to increase cannibalism. Each cannibal worm received a piece of head, a piece of mid-body and a piece of tail. Three pieces of liver equal in size to the pieces of planaria were given the control group of D. tigrina. Both experimental groups and the control group were fed again at the end of 5 days. Worms which failed to cannibalize during the first feeding were not included in the data presented.

The conditioning apparatus consisted of a lucite trough and Grass S-4 stimulator similar to the apparatus described by Barnes \& Katzung (1963). The light stimulus was $729 \mathrm{ft}-\mathrm{c}$ emitted by two $100 \mathrm{w}$ incandescent lamps. The light and shock cycles were controlled by automatic timers with a switch to interrupt the timing sequence. Ss were placed in the trough filled with appropriate media and allowed three to five minutes to become habituated. Light was administered for four seconds and during the fourth second a $100 \mathrm{cps}, 10 \mathrm{v}$ dc shock was administered with the polarity adjusted so that the head of $\mathrm{S}$ was toward the cathode. If $\mathrm{S}$ showed a marked turn either right or left so that the angle of the body was $45^{\circ}$ or more during the first three seconds, the sequence was interrupted, light was extinguished and shock was not administered. A variable inter-trial-interval of 30 to 120 seconds was used. All Ss were given 10 blocks of 20 trials and received one block of trials each day. During the first block no shock was used. Only turns of 450 or more made during the first three seconds of light were scored as responses. Half of the Ss were coded so that $\mathrm{E}$ did not know whether a particular S had eaten liver, conditioned worm or naive worm.

An analysis of variance was carried out on the results obtained using D. tigrina in an 18 (subjects) $\times 10$ (block of trials) $\times 3$ (types of feedings) design. Tests of significance were made for the main and interaction 


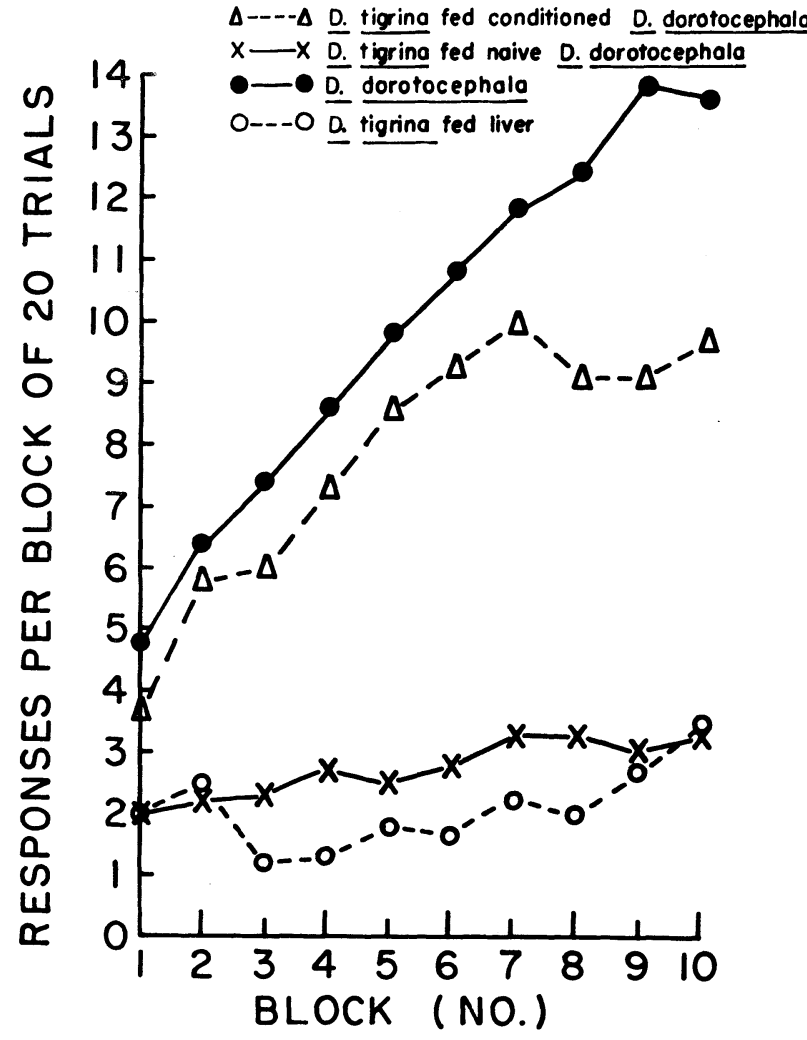

Fig. 1. Mean responses per block of 20 trials in successive blocks of trials.

effects. The feeding $(F=71.69 ; d f=2 / 15)$ and block $(F=13.69 ; d f=9 / 135)$ main effects and the blocks $x$ feeding interaction effects $(F=5.83$; $d f=18 / 135)$ were all significant at the .005 level. It is clear from the data summarized in Fig. 1 that these effects were largely due to the increasing number of responses made at each subsequent block by the group of D. tigrina which had been fed conditioned D. dorotocephala. D. tigrina fed naive $D$. dorotocephala were no more conditioned after 200 trials than D. tigrina fed only liver. Clearly D. dorotocephala can be instrumentally conditioned whereas D. tigrina show little if any conditioning using this same procedure.

Other investigators have reported conditioning of $D$. tigrina (Jacobsen, 1962). Conditioning of D. tigrina has not been demonstrable in this laboratory by either the classical procedure of Barnes \& Katzung (1963) or the procedure described above.

The two species used here are morphologically and ecologically well separated and appear genetically distinct. Thus, it may be inferred that i). dorotocephala possesses a genetic potential for conditioning by the avoidance training procedure which D. tigrina does not possess. However, some factor resulting from the conditioning of $D$. dorotocephala was transferable through cannibalism to D. tigrina since they were subsequently conditionable.

In the reports of McConnell (1962) and Hartry et al (1964) a change in rate of conditioning was demonstrated in animals already possessing the potential for that conditioning. In contrast, the present study demonstrates conditioning in animals previously not conditionable by the procedure employed. Further, this change in behavioral potential was mediated by a transferable factor resulting from training of conditionable planaria. Future experiments might reveal that other types of treatment such as photic stimuli, shock or handling will also produce this factor. The important point is that a factor can be acquired through cannibalism that overcomes a genetic deficit in learning ability. 2

\section{Referenees}

Barnes, C. D., \& Katzung, B. G. Stimulus polarity and conditioning in planaria. Science, 1963, 141, 728.

Best, J. B., \& Rubinstein, I. Maze learning and associated behavior in planaria. J. comp. physiol. Psychol., 1962, 55, 560.

Griffard, C. D., \& Peirce, J. F. Conditioned discrimination in the planarian. Science, 1964, 144, 1472.

Hartry, A. L., Keith-Lee, P., \& Morton, w. D. Planaria: Memory transfer through cannibalism reexamined. Science, 1964, 146, 274 .

Jacobson, A. L. Learning in flatworms and anellids. Psychol. Bull., 1962, 60, 74 .

Lee, R. M. Conditioning of a free operant response in planaria. Science, 1963, 139, 1048.

McConnell, J. V. Memory transfer through cannibalism in planarians. J. Neuropsychiat., 1962, 3, (Suppl. 1), 542.

\section{Notes}

1. Dugesia tigrina were obtained from Carolina Biological Supply, Burlington, North Carolina, as "brown" planaria. Dugesia dorotocephala were obtained from General Biological Supply House, Chicago. Both species were identified according to the key given in Fresh-water Invertebrates of the United States, by R. W. Pennak, (Ronald Press, New York, N. Y., 1953). Pp. 130-140.

2. We thank Sallie Marie Burns for her technical assistance. 